\title{
Insulin aspart revisited: new and clinical differential aspects versus other rapid-acting insulin analogs
}

\author{
Francisco Javier Ampudia-Blasco ${ }^{1 *}$, Fernando Rico-Villademoros ${ }^{2 \dagger},{\text { Xavier } \operatorname{Cos}^{3+} \text { and Domingo Orozco-Beltrán }}^{4+}$ \\ *Correspondence: Francisco.J.Ampudia@uv.es \\ These authors contributed equally to this work. \\ 'Diabetes Reference Unit, Endocrinology and Nutrition Department, Clinic University Hospital of Valencia and Department of \\ Medicine, University of Valencia, Valencia, Spain. \\ ${ }^{2}$ COCIENTE S.L., Madrid, Spain. \\ ${ }^{3}$ Sant Marti de Provençals Primary Care Centres, Barcelona, Spain. \\ ${ }^{4}$ CaboHuertas Primary Care Centre, Research Unit, San Juan Hospital, Alicante, Spain.
}

\begin{abstract}
The gradual deterioration of the pancreatic $\beta$-cell function in type 2 diabetes mellitus (T2DM) patients prompts the progressive introduction of more complex treatments, including the initiation of insulin in many patients. Rapid-acting insulin analogs (aspart, lispro, and glulisine) show advantages over human regular insulin due to their rapid absorption, short duration, and higher maximum insulin peaks. We reviewed the differential aspects of insulin aspart, its potential role in various strategies for intensifying insulin treatment in T2DM and its use in special situations such as older patients, pregnant women with diabetes, and treatment of hyperglycemic crises.
\end{abstract}

keywords: Type 2 diabetes mellitus, hyperglycemia, rapid-acting insulin analogs, aspart, basal-bolus therapy, stepwise therapy

\section{Introduction}

Diabetes mellitus, especially type 2 diabetes mellitus (T2DM), remains an important public health problem given its worldwide prevalence and the associated morbidity and mortality. Progressive deterioration of pancreatic $\beta$-cell function over time necessitates initiation of insulin treatment in a significant proportion of patients with T2DM for achieving or maintaining glycemic control targets.

Health care professionals who deal with T2DM patients are faced with the important task of adapting the glycemic control to individual targets, implementing new advances in treatment, and fighting against therapeutic inertia. The introduction of insulin analogs and development of new strategies for initiating and, particularly, intensifying insulin treatment, are among these new advances to be implemented. However, both patients and health professionals have some difficulties when initiating insulin treatment partly due to barriers raised from a lack of proper information regarding insulinization [1]. In this article, we will review some of the new and differential aspects of insulin aspart, a rapid-acting insulin analog (RAIA), its potential role in various strategies for insulin intensification, and its use in special situations such as the treatment of older patients, diabetic pregnant women or patients suffering from hyperglycemic episodes.

\section{Rapid-acting insulin analogs vs. regular human insulin}

RAIAs were developed to overcome some of the limitations of human regular insulin (HRI). In contrast to the physiological secretion of insulin induced by meal ingestion, $\mathrm{HRI}$ shows a slow initiation of action (15-60 minutes after injection), which requires administration 30-45 minutes before meals, a late peak-effect at 2-4 hours, and a prolonged duration of action (5-8 hours) [2]. As a result, HRI administration is accompanied by postprandial hyperglycemia and an increased risk of late hypoglycemia before the next meal. Therefore, HRI should be administered $30-45$ minutes before meals, a requirement that many patients do not meet [3].

As previously shown with insulin aspart in adolescents with Type 1 diabetes mellitus (T1DM) [4], the dose of RAIAs should be adjusted in patients ingesting a high fat meal to maintain postprandial normoglycemia.

Unlike HRI, which forms dimers and, upon aggregation, hexamers, RAIAs are monomeric insulin even at high concentration, which enables an improved absorption process. Their greater capacity for in situ dissociation and diffusion into the capillaries gives them a characteristic pharmacokinetic profile with a rapid increase in plasma insulin concentrations shortly after injection [5]. In general, the various RAIAs (aspart, lispro, and glulisine) exhibit similar pharmacokinetic and pharmacodynamic properties [6-9]. An injection of a RAIA results in a higher maximum insulin peak in half the time when compared with that of HRI [10]. When compared with HRI, RAIAs are more effective in reducing postprandial glycemic excursions (the difference between preprandial glycemia and postprandial glycemia at 1.5-2 hours) and the incidence of late postprandial hypoglycemia [10]. Furthermore, these advantages of RAIA allow for an administration just immediately before a meal or even after ingestion,

(C) 2013 Ampudia-Blasco et al; licensee Herbert Publications Ltd. This is an Open Access article distributed under the terms of Creative Commons Attribution License (http://creativecommons.org/licenses/by/3.0). This permits unrestricted use, distribution, and reproduction in any medium, provided the original work is properly cited. 
Ampudia-Blasco et al. Internal Medicine Inside 2013,

http://www.hoajonline.com/journals/pdf/2052-6954-1-7.pdf

doi: $10.7243 / 2052-6954-1-7$

Table 1. Recommendations for glycemic control from the American Diabetes Association (2012).

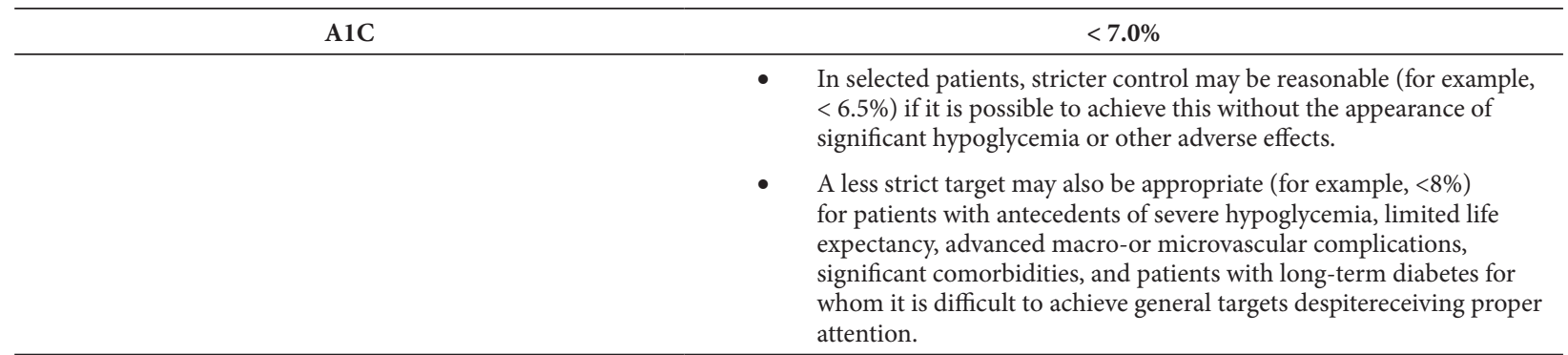

\begin{tabular}{|c|c|}
\hline Preprandial capillary plasma glycemia & $70-130 \mathrm{mg} / \mathrm{dL}(3.9-7.2 \mathrm{mmol} / \mathrm{L})$ \\
\hline Postprandial capillary plasma glycemia (1-2 h) & $<180 \mathrm{mg} / \mathrm{dL}$ \\
\hline $\begin{array}{l}\text { The targets should be individualized based on } \\
\text { - } \text { Duration of the diabetes } \\
\text { - } \text { Comollife expectancy } \\
\text { - Known cardiovascular disease or advanced } \\
\text { - } \text { microvascular complications } \\
\text { - Individual patient considerations }\end{array}$ & \\
\hline
\end{tabular}

If $\mathrm{AlC}$ targets are not reached despite having achieved those

for preprandialglycemia, the targets should be focused on

postprandial glycemia.

Adapted from the American Diabetes Association (2012) [1].

which is an aspect particularly appreciated by patients. Additionally, unlike HRI, the duration of action does not increase significantly with increasing dose of insulin aspart or glulisine $[9,11]$. Finally, the patient's perception of the RAIA is another important element to consider. In an observational study involving 66,726 patients with T2DM, the use of insulin analogs was also associated with an improvement in the quality of life [12].

\section{Differential aspects of insulin aspart compared with other insulin}

Although few comparative studies have been conducted among these types of insulin, a review of the results of the various randomized clinical trials indicates that all three RAIAs present similar effectiveness and safety [13]. However, some differences in physicochemical stability among them could be clinically relevant in some situations, as in continuous subcutaneous infusion of insulin (CSII or insulin pumps). In our setting, this is a treatment reserved almost exclusively for patients with T1DM. Insulin molecules are known to suffer structural changes and molecular aggregation during the process of production, storage, and later use. These changes can result in the formation of fibrils, insulin precipitation, and possibly catheter occlusions under CSII therapy [14].

All three RAIAs have demonstrated a greater stability than HRI. However, studies have shown that insulin aspart is the insulin with the least tendency to precipitate under adverse conditions, both in vitro and in vivo, being the insulin that offers the least risk of occlusion when used with insulin pumps, especially in comparison with glulisine [14].
Furthermore, the results of a single-center, randomized, double-blind, cross-over trial in 20 patients with T1DM on CSII also indicate the possible advantages of aspart in comparison with lispro in terms of patient tolerance and satisfaction [15].

\section{Insulin aspart in various clinical situations Stepwise approach for insulinization in type 2 diabetes: role of insulin aspart}

Treatment of T2DM usually begins with medical nutrition therapy and physical exercise, unless the patients consult with obvious hyperglycemia [16]. The American Diabetes Association (ADA) and the European Association for the Study of Diabetes (EASD) recommend adding metformin from the onset of the disease because of its beneficial effects on glycemic and weight control, its reduced cost, and the low incidence of side effects [17]. However, treatment with oral glucose-lowering drugs by monotherapy or in combination, although initially effective, is insufficient over time to achieve or maintain the target for glycemic control [16].

\section{Targets for glycemic control}

(Table 1) Currently, the ADA recommends to achieve/maintain glycated hemoglobin (A1C) less than 7\% for most patients with diabetes [18]. Additionally, the American Academy of Clinical Endocrinologists and the American College of Endocrinology both recommend a goal of less than $6.5 \%$, which is even more demanding [19]. Nevertheless, this goal should be individualized based on the characteristics of each patient (Table 1). Thus, the Spanish Diabetes Society 
Ampudia-Blasco et al. Internal Medicine Inside 2013,

http://www.hoajonline.com/journals/pdf/2052-6954-1-7.pdf

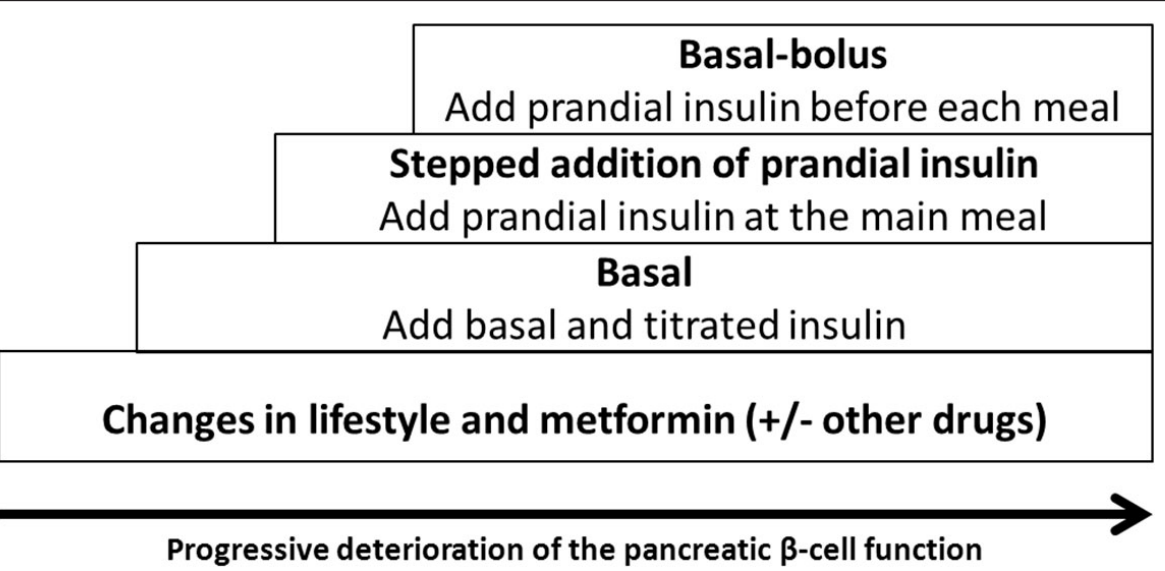

Figure 1. Stepped treatment of diabetes adjusted to the progression of the disease. The progressive deterioration of beta cells in the pancreas also supports the progressive intensification of treatment in patients with type 2 diabetes mellitus until an introduction of insulin treatment in addition to treatment with oral agents is achieved. Treatment with insulin traditionally begins with basal insulin, and, as the disease progresses, the introduction of prandial insulin becomes necessary. This progressive intervention can also be initiated by adding insulin to the principal meal and progressing to the basal-bolus strategy in which the patient receives prandial insulin prior to each meal.

(SDS) along with other national scientific societies, including the semFyC (Spanish Society of Family and Community Medicine) and the SEMERGEN (Spanish Society For Rural and General Medicine), recommends an A1C of less than $7 \%$ as a general target, but a stringent requirement (less than $6.5 \%$ ) is recommended for young, recently diagnosed patients without complications. Alternatively, in patients with advanced chronic complications such as those over 70 years of age or those who have a longer disease duration, a less rigorous glycemic goal (i.e., less than 7.5\%) is recommended [20].

\section{Initiation of insulin treatment}

When necessary, treatment with insulin usually begins with the introduction of basal insulin (detemir, glargine, or neutral protamine Hagedorn [NPH]). Less often, treatment is initiated with the administration of prandial insulin (that is, an RAIA or HRI) before the principal meals or with premixed insulin (a combination with fixed doses of a prandial insulin and a basal insulin).

The 4T study (Treating to Target in Type 2 Diabetes) was designed to evaluate which of the three options was the best for initiating treatment with insulin in patients with T2DM. In this open-label clinical trial, 708 T2DM patients who presented with inadequate levels of A1C (7-10\%) despite treatment with maximum doses of metformin and sulfonyl ureas were randomized to receive treatment with biphasic insulin, aspart 3 times a day or insulin detemir 1 or 2 times a day for the first year, optimizing, if necessary, with additional injections of either detemir or aspart insulin for up to three years [21]. At 52 weeks, the A1C levels were similar in patients who received biphasic insulin or prandial insulin ( $7.3 \%$ vs. $7.2 \%$, respectively; $p=0.08)$, although the levels were higher in those receiving basal insulin (7.6\%; $p<0.001$ for the two comparisons). However, the frequency of hypoglycemia and weight gain were significantly reduced in the basal insulin group [21]. Conversely, after 3 years, all three groups achieved similar levels of $\mathrm{A} 1 \mathrm{C}$ with a reduced frequency of hypoglycemia and weight gain in the basal insulin group [22].

The 4T study indicated that the choice of insulin for initiating treatment is not relevant because in the ensuing months/years, most patients will require an intensification of their insulin treatment to achieve/maintain the same degree of glycemic control. Consequently, initiating insulinization with basal insulin (detemir) appears to be a good option due to the smaller number of required injections, reduced risk of hypoglycemia, and lower weight gain. This procedure has also been recommended by a consensus of the ADA and EASD [17].

\section{Intensification of insulin treatment}

An intensification of the insulin treatment may be necessary if the target for glycemic control is not achieved despite adequate titration of basal insulin. Intensification could be achieved with two or three shots of premixed insulin or, as recently demonstrated, with the introduction of increasing prandial insulin doses or basal-bolus therapy if necessary. In the past, premixed insulin has been frequently used for insulin intensification. However, although it is effective in reducing hyperglycemia, this treatment is often associated with an increased risk of hypoglycemia and weight gain. Furthermore, the use of premixed insulin is a therapeutic scheme with little flexibility that frequently requires rigid 
meal schedules [23]. Conversely, a basal-bolus therapy continues to be the most effective strategy of insulin treatment even in patients with T2DM [23]. Thus, to help adaptation of the patient to a progressive intensification of insulin treatment, other options have been proposed, such as the stepped addition of prandial insulin before meals. This strategy consists in a progressive introduction of increasing doses of prandial insulin, beginning with the main perceived meal or, alternatively, the meal with the greatest impact on postprandial glucose values while continuing treatment with basal insulin and oral agents (metformin) (Figure 1).

A 6-month, randomized, open-label clinical trial that evaluated the addition of a dose of insulin glulisine at the main meal in 106 patients with T2DM confirmed this approach as an effective strategy for insulin intensification [24]. Later trials involving the stepped addition of prandial insulin indicated that this strategy is also effective independent of both, the meal (breakfast or the meal with the highest glucose excursion) for which the prandial insulin (glulisine) is added [25], and the method used to adjust the dose [26]. In some studies, this therapeutic option seems to be similarly effective when compared with basal-bolus therapy $[27,28]$.

In the STEP-wise study, which included 296 T2DM patients, the sequential addition of 1, 2, or 3 insulin aspart injections to a regimen of insulin detemir, previously optimized during a 12-week pre-inclusion period, was evaluated using a 48week, randomized, open-label design. Insulin aspart was added using one of the following strategies: (a) adding it to the principal meal and adjusting the dose based on the premeal glucose values ("SimpleSTEP") or (b) adding it to the meal with the largest increase in postprandial glucose and adjusting the dose as a function of the postmeal glucose value ("ExtraSTEP"). The number of injections was increased with both strategies in the case of insufficient therapeutic effect (A1C $\geq 7 \%$ ) [29]. The second and third administrations of aspart were performed at intervals of 12 weeks. The analysis at the conclusion of the study indicated that after 48 weeks of treatment, the two methods for intensifying the insulin treatment were equally effective. The A1C level was reduced by $1.2 \%$, and no differences were detected between the strategies in episodes of hypoglycemia or increase in weight. At the end of the treatment period, more than $75 \%$ of the patients received the 3 injections of aspart. In clinical practice, the strategy of evaluating glycemia before ingestion may be easier for the patient and is actually the most often used in our country.

In summary, these studies indicate that the progressive introduction of prandial insulin, when added to a regime of basal insulin in combination with oral agents, is overall a good option for the transition to basal-bolus therapy. This strategy presents an adequate risk-benefit ratio and can facilitate the acceptance by the patient to increasingly complex therapeutic regimens.

\section{Other relevant clinical situations} Transference from basal or premixed insulin to a basal-bolus strategy

To make the transference possible, one should initially calculate the patient's total daily dose requirements [30]. Generally, the daily insulin dose represents the total previous daily basal insulin dose (approximately $0.5 \mathrm{IU} / \mathrm{kg} /$ day) or the sum of the total daily dose if the patient has received premixed insulin. Next, the total daily dose is distributed to approximately $50 \%$ of basal insulin and $50 \%$ of prandial insulin, dividing the total amount by thirds for each meal (or between $10 \%$ and 20\%). Finally, one should calculate a complementary correction scale with rapid-acting insulin. The correction factor estimates the reduction in plasma glucose per unit of insulin, as applied in accordance with the desired values of preprandial glucose and those actually presented by the patient. An empirical rule has been proposed in which the correction factor (the reduction of glycemia with 1 IU of insulin) can be calculated by dividing 1800 by the total daily dosage of insulin if RAIAs are used or by dividing 1500 by the total daily dosage if HRIs are used. In this example, if the patient is treated with detemir 0-0-32 IU and aspart 4-6-5, the sensitivity factor will be as follows: $1800 \div(32+15)=38$ ( 1 IU aspart reduces glycemia to $\sim 40 \mathrm{mg} / \mathrm{dL}$ ).

In addition, adjustments in the insulin dose should be continuous over time. Doses of basal insulin need to be titrated based on the fasting glucose levels (and before the meal in the case of 2 doses of basal insulin), whereas prandial insulin doses should be adjusted based on preprandial or postprandial glycemia according to the selected adjustment strategy.

\section{Insulinization in older patients}

Initiation of insulin therapy in older patients with diabetes is even more difficult than in young adults. These patients frequently exhibit cognitive problems, visual disorders or are living alone. In such cases, outpatient intensification of insulin treatment is complicated and sometimes impossible [31]. Furthermore, aged diabetic patients are more prone to the deleterious effects of hypoglycemia, which may be associated with other problems such as falls or other complications [31]. Nevertheless, age should not be an obstacle for beginning an insulin treatment that is considered necessary according to the glycemic control targets and the clinical situation of the patient [32]. However, goals for glycemic control should be less strict in older patients, especially in those with a limited life expectancy, [20].

Due to its simplicity, starting with basal insulin before bedtime, or even in the morning, is the best method to initiate insulin treatment in aged diabetic patients [32]. Long acting insulin analogs such as detemir or glargine allow improved adaptation to the physiological needs with a more predictable and consistent glycemic control 
Ampudia-Blasco et al. Internal Medicine Inside 2013,

http://www.hoajonline.com/journals/pdf/2052-6954-1-7.pdf

doi: $10.7243 / 2052-6954-1-7$

and a reduced risk of hypoglycemia [31].

As in younger adults, the addition of prandial insulin in older patients may be necessary for the control of excessive hyperglycemia when basal insulin alone is not enough. In most cases, RAIAs also offer a better physiological action profile when compared with HRIs. Aspart has demonstrated a consistent pharmacokinetic profile in older people with diabetes, which is similar to that observed in younger adults in a randomized, double-blind, cross-over clinical trial in 19 patients with T2DM [33]. In addition, for those patients with renal insufficiency, PK/PD characteristics of aspart do not appear to vary significantly in the clinic according to the results of a small, phase I, pharmacokinetic study [34]. Furthermore, RAIAs offer an additional advantage in aged people due to a greater flexibility of administration with meals, especially for seniors who are institutionalized or for whom ingestion of foods may be unpredictable or occasionally compromised.

\section{Incidental hyperglycemia at the outpatient clinic}

Acute complications of diabetes include both hypoglycemia and hyperglycemic decompensations such as diabetic ketoacidosis or the hyperglycemic hyperosmolar state.

Diabetic ketoacidosis is a complication induced by an acute deficiency of insulin [35]. Precipitating factors in the development of diabetic ketoacidosis include infection, pancreatitis, myocardial infarction, cerebrovascular accidents, and drugs [36]. Although it occurs almost exclusively in T1DM patients, diabetic ketoacidosis may also appear in T2DM patients. If the patient presents with signs or symptoms of diabetic ketoacidosis, he/she should be sent urgently for treatment to the hospital. However, an early intervention using intravenous fluid therapy such as saline solution and treatment with rapid-acting insulin may be helpful; these, particularly, are evaluated first in a primary care setting [37]. Although intravenous administration of insulin is preferred in these patients, RAIAs may also be administered intramuscularly or subcutaneously if intravenous administration remains impossible.

A hyperosmolar hyperglycemic state is characterized by excessive hyperglycemia, extreme dehydration, and an increase in plasma osmolarity. This state occurs in patients with T2DM in whom a remaining persistent insulin secretion is able to prevent ketone production and the development of ketoacidosis [35]. However, mortality is high in these clinical situations, especially in patients of advanced age. The main clinical findings are serious dehydration and changes in mental status, which range from confusion to deep coma. Except for serious situations, treatment outside of the hospital should take place slowly, beginning with a saline solution infusion and administration of an individualized dose of rapid insulin by the intravenous (approximately $0.10-0.15 \mathrm{IU} / \mathrm{kg}$ ) or subcutaneous route (approximately 12-16 IU) [37].

Although the general recommendation for treatment of these hyperglycemic crises is the use of HRI, RAIAs are also an effective alternative [36]. In the case of insulin aspart, its use in acute situations has been evaluated in two randomized, open-label clinical trials in comparison with regular insulin in 45 patients admitted with diabetic ketoacidosis [38] and in 176 patients with T2DM and hyperglycemia seen at the emergency department [39]. In both cases, aspart demonstrated similar efficacy and tolerability when compared with HRI.

Finally, although making an appropriate diagnosis and selecting the most convenient therapeutic action against a hyperglycemic crisis is obviously more complex than previously described, interested readers are invited to review the latest recommendations of the ADA on this topic [36].

\section{Diabetes and pregnancy}

Among the types of prandial insulin, in addition to regular human insulin, both aspart and lispro have been evaluated specifically for this clinical situation (risk category B: no risks have been described for humans, with their use accepted during pregnancy) $[40,41]$. Thus, in a randomized, openlabel trial conducted in 322 women with T1DM who were pregnant or planning to be pregnant, insulin aspart was at least as effective as HRI for glycemic control and seemed to offer some advantages over HRI for postprandrial glucose control and preventing severe hypoglycemia [40]. In a randomized, open-label trial in 33 pregnant women with T1DM, insulin lispro provided similar glycemic control when compared with HRI [41]. Concerning basal insulin, only NPH insulin and insulin detemir have been studied in specific randomized clinical trials [42] and were therefore also recently included in the risk category $B$ for pregnancy. In this non-inferiority, randomized clinical trial conducted in 310 pregnant women with T1DM, insulin detemir was non-inferior regarding glycemic control but resulted in lower fasting plasma glucose compared with insulin NPH [42]. Given that the information available regarding glargine use in pregnancy corresponds only to isolated clinical cases or small case studies, this long-acting insulin analog continues to be listed in the risk category $C$ for pregnancy (fetal risk cannot be excluded when evaluating risk/benefit).

\section{Conclusions}

The gradual deterioration of the pancreatic $\beta$-cell function in T2DM patients prompts to the progressive introduction of more complex treatments, which make the introduction of insulin necessary for a large proportion of these patients. Usually, adding basal insulin is the first step in starting insulinization, advancing, if needed, to a progressive addition of prandial insulin, and finally, if necessary, to administration of prandial insulin at every meal (basalbolus). At present, the latter strategy is considered the best in reproducing the physiological insulin secretion in healthy individuals.

Currently, RAIAs (aspart, lispro, and glulisine) offer 
some advantages as prandial insulin due to their rapid absorption, short duration, and increased insulin peak in comparison with $\mathrm{RHI}$ [13]. These aspects result in a greater flexibility in relation to the meals, more effective reduction in postprandial hyperglycemia, and reduced incidence of late postprandial hypoglycemia [13]. Among RAIAs, aspart has demonstrated the best physicochemical stability, which translates into targeted clinical benefits for some groups of patients such as those (largely T1DM patients) who use a continuous subcutaneous infusion of insulin [14]. This insulin has also been evaluated with success for new insulinization strategies such as the stepped addition of prandial insulin that have been developed to facilitate the transition to more complex therapies including basal-bolus therapy [29]. In addition, aspart has been evaluated in various patient populations and clinical contexts, such as in aged diabetic patients [33], in those with renal insufficiency [34], during pregnancy [40] and for treatment of hyperglycemic episodes [38]. In these situations, aspart has proven to be effective, safe, and consistent in maintaining its pharmacokinetic advantages.

\section{Competing interests}

Ampudia-Blasco has received consulting/lecture fees from Abbott, Bristol-Mayers-Squibb, GSK, LifeScan, Lilly, Madaus, MannKind Corp., Medtronic, Menarini, Merck Farma y Química, S.A., MSD, Novartis, Novo Nordisk, Pfizer, Roche, Sanofi-Aventis, Schering-Plough and Solvay and research grants from Astra-Zeneca, Bayer, GSK, Life-Scan, Lilly, MSD, Novo Nordisk, Pfizer, Sanofi-Aventis and Servier.

Rico-Villademoros has received consulting fees from Novo Nordisk, Pfizer, Roche, Lilly and Servier. Rico-Villademoros has provided editorial support for the preparation of this manuscript, and this support has been funded by Novo Nordisk.

Orozco-Beltran has received consulting/ lecture fees from de Bristol-Myers-Squibb, Lilly, MSD, Novo Nordisk, and Sanofi-Aventis.

Cos-Claramunt has received consulting/lecture fees from Abbott, Bayer, Bristol-Mayers-Squibb, GSK, Lilly, MSD, Novo Nordisk, Novartis and Sanofi-Aventis and research grants from Astra-Zeneca, Novo Nordisk and Sanofi-Aventis.

\section{Authors' contributions}

Ampudia-Blasco was responsible for the conception of this review and prepared an outline, drafted the manuscript and approved the final version; RicoVillademoros revised the outline, drafted the manuscript and approved the final version; Cos-Claramunt and Orozco Beltran revised the outline, revised the manuscript critically and approved the final version.

Acknowledgement

The authors would like to thank Rico-Villademoros from COCIENTE S.L. for writing assistance, which was funded by Novo Nordisk. Novo Nordisk reviewed this manuscript for medical accuracy.

\section{Publication history}

Editor: Sahar Ali Ibrahim, Taibah University, Saudi Arabia. Received: 08-Apr-2013 Revised: 07-May-2013

Re-Revised: 28-May-2013 Accepted: 05-Jun-2013

Published: 19-Jun-2013

\section{References}

1. Peyrot M, Rubin RR, Lauritzen T, Snoek FJ, Matthews DR and Skovlund SE: Psychosocial problems and barriers to improved diabetes management: results of the Cross-National Diabetes Attitudes, Wishes and Needs (DAWN) Study. Diabet Med 2005, 22:1379-85. | Article | PubMed

2. Heinemann $L$ and Richter B: Clinical pharmacology of human insulin. Diabetes Care 1993, 16 Suppl 3:90-100. | Pdf | PubMed

3. Overmann $\mathrm{H}$ and Heinemann $\mathrm{L}$ : Injection-meal interval: recommendations of diabetologists and how patients handle it. Diabetes Res Clin Pract 1999, 43:137-42. | Article | PubMed

4. Lodefalk M, Aman J and Bang P: Effects of fat supplementation on glycaemic response and gastric emptying in adolescents with Type 1 diabetes. Diabet Med 2008, 25:1030-5. | Article | PubMed

5. Brange $J$ and Langkjoer L: Insulin structure and stability. Pharm Biotechnol 1993, 5:315-50. | PubMed

6. Howey DC, Bowsher RR, Brunelle RL and Woodworth JR: [Lys(B28), Pro(B29)]-human insulin. A rapidly absorbed analogue of human insulin. Diabetes 1994, 43:396-402. | PubMed

7. Mudaliar SR, Lindberg FA, Joyce $M$, Beerdsen $P$, Strange $P$, Lin $A$ and Henry RR: Insulin aspart (B28 asp-insulin): a fast-acting analog of human insulin: absorption kinetics and action profile compared with regular human insulin in healthy nondiabetic subjects. Diabetes Care 1999, 22:1501-6. | Article | PubMed

8. Homko C, Deluzio A, Jimenez C, Kolaczynski JW and Boden G: Comparison of insulin aspart and lispro: pharmacokinetic and metabolic effects. Diabetes Care 2003, 26:2027-31. | Article | PubMed

9. Becker RH: Insulin glulisine complementing basal insulins: a review of structure and activity. Diabetes Technol Ther 2007, 9:109-21. | Article I PubMed

10. Hirsch IB: Insulin analogues. N Eng/ J Med 2005, 352:174-83. | Article | PubMed

11. Nosek L HL, Kaiser M: No increase in the duration of action with raising doses of insulin aspart. Diabetes 2003, 52(Suppl 1):A128.

12. Shah S, Zilov A, Malek R, Soewondo P, Bech O and Litwak L: Improvements in quality of life associated with insulin analogue therapies in people with type 2 diabetes: results from the A1chieve observational study. Diabetes Res Clin Pract 2011, 94:364-70. | Article I PubMed

13. Home PD: The pharmacokinetics and pharmacodynamics of rapidacting insulin analogues and their clinical consequences. Diabetes Obes Metab 2012, 14:780-8. | Article | PubMed

14. Bode BW: Comparison of pharmacokinetic properties, physicochemical stability, and pump compatibility of 3 rapid-acting insulin analoguesaspart, lispro, and glulisine. Endocr Pract 2011, 17:271-80. | Article | PubMed

15. Siegmund T, von Amelunxen S, Kaiser M, Oeffner A, Schumm-Draeger PM: Pump compatibility of insulin aspart compared to insulin lispro with respect to catheter complications and dermal/subcutaneous irritations in type 1 diabetes patients undergoing insulin pump therapy (CSII). Diabetes 2005, 54(suppl 1):A105.

16. Ampudia-Blasco FJ, Rosenstock J: Estrategias de insulinización en la diabetes mellitus tipo 2. Av Diabetol 2008, 24:7-20. | Article

17. Inzucchi SE, Bergenstal RM, Buse JB, Diamant M, Ferrannini E, Nauck M, Peters AL, Tsapas A, Wender R and Matthews DR: Management of hyperglycaemia in type 2 diabetes: a patient-centered approach. Position statement of the American Diabetes Association (ADA) and the European Association for the Study of Diabetes (EASD). Diabetologia 2012, 55:1577-96. | Article | PubMed

18. Standards of medical care in diabetes-2012. Diabetes Care 2012, 35 Suppl 1:S11-63. | Article | PubMed Article | PubMed Abstract

19. Rodbard HW, Jellinger PS, Davidson JA, Einhorn D, Garber AJ, Grunberger G, Handelsman Y, Horton ES, Lebovitz H, Levy P, Moghissi ES and Schwartz SS: Statement by an American Association of Clinical Endocrinologists/American College of Endocrinology consensus panel on type $\mathbf{2}$ diabetes mellitus: an algorithm for glycemic control. Endocr Pract 2009, 15:540-59. | PubMed 
Ampudia-Blasco et al. Internal Medicine Inside 2013,

http://www.hoajonline.com/journals/pdf/2052-6954-1-7.pdf

20. Menéndez Torre E, Lafita Tejedor J, Artola Menéndez S, Millán Núñez-Cortés J, Alonso García Á, Puig Domingo M, García Solans JR, Álvarez Guisasola F, García Alegría J, Mediavilla Bravo J et al: Recomendaciones para el tratamiento farmacológico de la hiperglucemia en la diabetes tipo 2. Av Diabetol 2010, 26:331-338. I Article

21. Holman RR, Thorne KI, Farmer AJ, Davies MJ, Keenan JF, Paul S and Levy JC: Addition of biphasic, prandial, or basal insulin to oral therapy in type 2 diabetes. N Engl J Med 2007, 357:1716-30. | Article I PubMed

22. Holman RR, Farmer AJ, Davies MJ, Levy JC, Darbyshire JL, Keenan JF and Paul SK: Three-year efficacy of complex insulin regimens in type 2 diabetes. N Engl J Med 2009, 361:1736-47. | Article | PubMed

23. Ampudia-Blasco FJ, Rossetti P and Ascaso JF: Basal plus basal-bolus approach in type 2 diabetes. Diabetes Technol Ther 2011, 13 Suppl 1:S75-83. | Article | PubMed

24. Owens DR, Luzio SD, Sert-Langeron C and Riddle MC: Effects of initiation and titration of a single pre-prandial dose of insulin glulisine while continuing titrated insulin glargine in type 2 diabetes: a 6-month 'proof-of-concept' study. Diabetes Obes Metab 2011, 13:1020-7. | Article | PubMed Article | PubMed Abstract

25. Lankisch MR, Ferlinz KC, Leahy JL and Scherbaum WA: Introducing a simplified approach to insulin therapy in type 2 diabetes: a comparison of two single-dose regimens of insulin glulisine plus insulin glargine and oral antidiabetic drugs. Diabetes Obes Metab 2008, 10:1178-85. | Article | PubMed

26. Del Prato S, Nicolucci A, Vespasiani G: Optimising basal plus insulin therapy in type 2 diabetes by telecare assistance for self-monitoring of blood glucose-the ELEONOR study. Diabetologia 2008, 51(Suppl 1):S452-S453.

27. Davidson MB, Raskin P, Tanenberg R, Vlajnic A, Hollander P: Effects of 1,2 or 3 prandial injections of insulin glulisine on glycemic control in type 2 diabetes patients on insulin glargine and oral drugs. Diabetes 2009, 58(Suppl 1):A132.

28. Raccah D, Haak T, Huet D, Monnier L, Ramon JS, Robertson D, Labard P, Penfornis A, OSIRIS Study Group: Stepwise intensification of prandial insulin versus basal-bolus insulin therapy in patients with type 2 diabetes mellitus. Diabetologia 2010, 53:S382.

29. Meneghini L, Mersebach H, Kumar S, Svendsen AL and Hermansen K: Comparison of $\mathbf{2}$ intensification regimens with rapid-acting insulin aspart in type 2 diabetes mellitus inadequately controlled by oncedaily insulin detemir and oral antidiabetes drugs: the step-wise randomized study. Endocr Pract 2011, 17:727-36. | Article | PubMed

30. Meneghini LF: Insulin for intensifying diabetes treatment. J Fam Pract 2011, 60:S21-8. | Article | PubMed

31. Seguí Díaz M: Aspectos prácticos en la insulinización del paciente anciano con diabetes. Av Diabetol 2010, 26:320-325. | Article

32. Munshi M, Blair E, Cooppan R: Diabetes in the older adult. In: Joslin's Diabetes Deskbook A guide for primary care providers, Edited by Baeser R. Boston, MA: Joslin Diabetes Center; 2010.

33. Krones $R$, Schutte $C$ and Heise $T$ : The rapid-acting properties of insulin aspart are preserved in elderly people with type 2 diabetes. Diabetes Obes Metab 2009, 11:41-4. I Article I PubMed

34. Holmes G, Galitz L, Hu P and Lyness W: Pharmacokinetics of insulin aspart in obesity, renal impairment, or hepatic impairment. $\mathrm{Br} J \mathrm{Clin}$ Pharmacol 2005, 60:469-76. | Article | PubMed Article | PubMed Abstract

35. Cooppan R, Baeser R, Shetty G: Acute complications. In: Joslin's Diabetes Deskbook A guide for primary care providers, Edited by Center JD. Boston, MA: 2010.

36. Kitabchi AE, Umpierrez GE, Miles JM and Fisher JN: Hyperglycemic crises in adult patients with diabetes. Diabetes Care 2009, 32:133543. | Article | PubMed Article | PubMed Abstract

37. España $\mathrm{C}$, Calvo R, Rivero MT: Urgencias en diabetes. In: $A B C D E$ en Emergencias Extrahospitalarias, Edited by Fernández-Obanza E: Praxis Medica; 2009.

38. Umpierrez GE, Cuervo R, Karabell A, Latif K, Freire AX and Kitabchi AE:
Treatment of diabetic ketoacidosis with subcutaneous insulin aspart Diabetes Care 2004, 27:1873-8. | Article | PubMed

39. Bernard JB, Munoz C, Harper J, Muriello M, Rico E and Baldwin D: Treatment of inpatient hyperglycemia beginning in the emergency department: a randomized trial using insulins aspart and detemir compared with usual care. J Hosp Med 2011, 6:279-84. | Article | PubMed

40. Mathiesen ER, Kinsley B, Amiel SA, Heller S, McCance D, Duran S, Bellaire $S$ and Raben A: Maternal glycemic control and hypoglycemia in type 1 diabetic pregnancy: a randomized trial of insulin aspart versus human insulin in 322 pregnant women. Diabetes Care 2007, 30:771-6. | Article | PubMed

41. Persson B, Swahn ML, Hjertberg R, Hanson U, Nord E, Nordlander E and Hansson LO: Insulin lispro therapy in pregnancies complicated by type 1 diabetes mellitus. Diabetes Res Clin Pract 2002, 58:115-21. | Article | PubMed

42. Mathiesen ER, Hod M, Ivanisevic M, Duran Garcia S, Brondsted L, Jovanovic L, Damm P and McCance DR: Maternal efficacy and safety outcomes in a randomized, controlled trial comparing insulin detemir with NPH insulin in $\mathbf{3 1 0}$ pregnant women with type 1 diabetes. Diabetes Care 2012, 35:2012-7. | Article | PubMed

\section{Citation:}

Ampudia-Blasco FJ, Rico-Villademoros F, Cos X and Orozco-Beltrán D: Insulin aspart revisited: new and clinical differential aspects versus other rapid-acting insulin analogs. Intern Med Inside 2013, 1:7. http://dx.doi.org/10.7243/2052-6954-1-7 